\title{
Materialised Identities: Cultural Identity, Collective Memory, and Artifacts
}

\author{
Richard Heersmink ${ }^{1}$
}

Accepted: 2 July 2021/Published online: 12 July 2021

(C) The Author(s), under exclusive licence to Springer Nature B.V. 2021

\begin{abstract}
This essay outlines one way to conceptualise the relation between cultural identity, collective memory, and artifacts. It starts by characterising the notion of cultural identity as our membership to cultural groups and briefly explores the relation between cultural and narrative identity (section 2). Next, it presents how human memory is conceptualised on an individual and collective level (section 3) and then distinguishes between small-scale and large-scale collective memory (section 4). Having described cultural identity and collective memory, it argues that cultural identity is materialised in the environment when we retrieve and construct collective memories by integrating information from our biological memory with information in artifacts or in other people's embodied brains (section 5). This essay ends with analysing how materialised cultural identities are constructed by using a niche construction approach from evolutionary biology (section 6).
\end{abstract}

\section{Introduction}

Cultural identity can be characterised as the membership to a cultural group such as a nation, religion, political group, generation, or family. These groups have historical narratives that characterise them in important ways and ensures their continuity over time. Shared memories of events constituting these narratives are referred to as collective memories, i.e., memories that a collective shares. Social interactions with other people as well as artifact-scaffolded practices embedded in cultural institutions remind us of events in these narratives in a way that is not possible without external aid. I will argue that some collective memories can be extended and distributed across embodied agents interacting with artifacts and other people. These collective memories are then not merely shared amongst group members, but the content and processes of collective memories can be distributed across two or more people. Cultural identity is

Richard Heersmink

richard.heersmink@gmail.com

1 Institute of Philosophy II, Ruhr-Universität Bochum, Universitätsstr. 150, 44780 Bochum, Germany 
materialised in the environment when we retrieve and construct collective memories by integrating information from our biological memory with information in artifacts or in other people's brains. To better understand how our cultural identities are materialised in institutions, social practices, and artifacts, I draw on niche construction theory from evolutionary biology and identify three types of cultural niche construction processes, namely the building, transferring, and using of cultural artifacts. By doing so, I bring into contact theories of collective memory and niche construction.

\section{Cultural Identity and Narrative Identity}

Cultural identity, characterised as the membership to a cultural group, is not an intrinsic property of persons, but is a relational social property, as it is developed and maintained in relation to cultural groups. This type of identity has been defined by social psychologist Henri Tajfel as "an individual's knowledge that he belongs to certain social groups together with some emotional and value significance to him of his group membership" (1972, p. 292). So, it is a sociocognitive structure with affective and normative significance to the individual. Our cultural identity has many facets as individuals belong to various cultural groups, having to do with nationality, regionality, religion, profession, hobbies, sports, music, art, gender, socioeconomic class, political groups, generation, family, and other groups with their own culture. One might, for example, self-identify as Australian, Melbournian, professional philosopher, soccer supporter, alternative rock fan, photography enthusiast, male, middle class, communitarian, Generation X-er, member of a family, etc. These groups have distinct cultures, meaning that they are characterised by a distinct set of practices, values, and norms.

Cultural identities are fluid and sometimes change over time. One might move to a new country or city, change profession, develop an interest in painting, and one's religious or political views may change. So, membership to some of the cultural groups one self-identifies with can (and sometimes do) change over time. As suggested above, we do not have one cultural identity but usually self-identify with a number of different cultural groups. Our overall cultural identity may be seen as the totality of our different cultural identities. This overall cultural identity is fluid and the nested pattern of the cultural groups we self-identify with shifts over time (Jenkins 2014). Also, membership to some of these cultural groups is not the result of conscious agency, whereas membership to others is. For example, one has no choice in where, when, or in which family one is born, whereas one's religion, profession, hobbies, and political views are (at least to some degree) the result of one's conscious choices.

There are different degrees of commitment to one's membership to cultural groups (Ellemers et al. 2002). As mentioned above, membership to cultural groups is characterised by a set of practices, values, and norms. Two people may both be born and live in Australia and, in that sense, both have an Australian national identity, but one of them may feel a stronger commitment to the practices, values, and norms that characterise Australian national identity. Likewise, two people may both self-identify as protestant, but may have different commitments to the practices, values, and norms that characterise their religious identity. Cultural identity thus means different things to different people. Importantly, there is often not a universal agreement about what it means to have a particular cultural identity. What I mean here is that there is no 
universal agreement amongst group members about what it exactly means to be Australian, communitarian, protestant, etc. Membership to these cultural groups exists on a continuum. There is, for example, individual variation in the dimensions that people attribute to being Australian such as the language and accent, worshipping of sport, cuisine, commitment to Western democratic values, multiculturalism, knowledge of its history, etc. Whilst there may be some core commitments characterising group membership, there are usually a lot of variables that group members do not agree upon.

The expression of cultural identity is done through institutions, practices, and artifacts. Universities, museums, libraries, archives, courts, churches, sport events, and music festivals as well as the practices and artifacts associated with these cultural institutions allow us to express our identities. ${ }^{1}$ So, for a person to express her protestant identity, she may go to church and participate in a service, praying, singing, reading from the bible, while being surrounded by the many religious artifacts and symbols. Or, for a person to express her identity as an alternative rock enthusiast, she may visit rock music festivals, dress in a particular way, dance in a particular way, and talk about particular topics. Participating in these institutions and practices enables us to express who we are, which often has a strong affective relevancy to the person, creating a sense of belonging. Artifacts, in particular, often play key symbolic roles in the expression of cultural identity. For example, one way to express American national identity is through the American flag, which features prominently on (government) buildings, airports, and people's houses, and is also used as a bumper sticker, fridge magnet, and on clothing. It is an important symbol of patriotism, national identity, and is even used in metaphorical expressions like "Rallying around the flag" (Schatz and Lavine 2007).

As Tajfel (1972) wrote, cultural identity is not a mere sociocognitive construct, it has affective significance, too. Participating in social activities and expressing one's cultural identity often causes us to feel a certain way. Religious ceremonies, commemorative services, sports events, political rallies, music festivals, and many other activities that express, affirm, and remind one of one's cultural identity often induce strong affective responses in individuals. During such activities, we may, for example, feel pride, joy, sadness, anger, a sense of unity, reassurance, and other affective states. Philosopher Robert Wilson $(2001,2005)$ argues that affective states are sometimes socially manifested, which means that such states can only be realised (or manifested) when participating in group activities. On this view, individuals engage in some forms of affect only insofar as they constitute part of a social group. Wilson calls this "the social manifestation thesis". Importantly, the expression of cultural identity also has a mnemonic function, as participating in these institutions and artifact-scaffolded practices reminds individuals of who they are and which cultural groups they belong to.

Cultural identity is distinct from but overlaps with narrative identity. One's narrative identity is constituted by a large cluster of integrated memories of personal experiences (Schechtman 1996, 2011). It can be characterised as a subjective, affective, and personal story containing a mostly accurate chronological depiction of a series of connected events and experiences that constitute the self and provides continuity of self to some degree (Heersmink 2020b). The person in question is the protagonist in these memories, which are meaningfully connected through a process of emplotment

\footnotetext{
${ }^{1}$ However, a reviewer pointed out that these institutions, practices, and artifacts do more than just express our cultural identities. They also have other, more practical functions.
} 
(Ricoeur 1984). When prompted, either by oneself or by someone else, one should be able to think through or articulate (parts of) the narrative. What makes you the particular person you are and what distinguishes you from other persons is your unique autobiographical narrative, your remembered experiences. And this narrative ensures that you experience a sense of personal continuity over time to some degree.

The relation between cultural identity and narrative identity is complex. One way to conceptualise this relation is as follows. The content of one's personal memories and narrative are determined by the experiences one has and the activities one engages in. This, in turn, is shaped by the various cultural groups one self-identifies with. For example, a soccer fan will go to soccer matches or watch them on TV and thus have memories of those experiences, a protestant will go to church, baptise her children, and so on, and will have memories of those experiences. Expressions of cultural identity often become personal memories in an overall narrative. Also, the values and norms that characterise group membership will shape one's behaviours. Protestants or communitarians will (often) act in ways that are consistent with their moral code, thereby promoting some actions but not others. This, too, will shape the sorts of experiences one has and thus also the content of one's personal memories and narrative. I want to suggest that cultural and narrative identity are two layers in an overall identity system. Conceptually, one can identify and distinguish between cultural identity and narrative identity, but in actual persons they mesh and are layers in one's overall identity system. ${ }^{2}$

Like persons, cultural groups have a narrative that characterises their identity and ensures continuity over time. ${ }^{3}$ Cognitive psychologist Qi Wang points out that: "Just as autobiographical memory serves a primary function of defining the individual self, collective memory sustains a community's very identity and makes possible the continuity of its social life and cultural cohesion" (2008, p. 307). Nations, regions, religions, professions, sport teams, music genres, art genres, social classes, political groups, generations, and families all have historical narratives that characterise them in important ways (László 2007; Liu and László 2007). American national identity is characterised by events in its past such as the waves of immigration from different countries in the 18th, 19th and twentieth century, the civil war, WW1, the great depression, WW2, the cold war, the civil rights movement, the counterculture revolution, 9/11, and many other important historical events. Protestant identity is characterised by its history, including the actions of important historical figures such as Martin Luther and the protestant reformation in the sixteenth century, resulting in the current protestant principles. And the identity of alternative rock depends on its history, including its origin in the 1970s, its heyday in the 1990s with the formation of bands like Nirvana, Pearl Jam, and Smashing Pumpkins and the shows and festivals they played at. In order to understand the current practices, values, and norms characterising a cultural group, one must look at its history.

\footnotetext{
2 The subject of experience (Gallagher 2000; Schlicht 2018), which is the entity that has experiences, is also part of this larger identity system. Briefly, the relation between these can be seen as follows. Expressions of cultural identity are experiences that the subject has and some of these are consolidated in the embodied brain and can become part of a larger narrative identity.

${ }^{3}$ Whilst both persons and cultural groups have narratives, these narratives are ontologically different. One difference is that personal narratives are about experiences of individuals with one main character, whereas cultural narratives are about experiences of groups of individuals with more than one character.
} 
Before moving on to discussing individual and collective memory, it is helpful to distinguish between the identity of the group as a whole and the identity of the persons who are members of that group. The focus in this paper is on the identity of the persons who are members of cultural groups and on how that identity is influenced by being part of a group. In the next two sections, I will look at how the historical narrative of groups is remembered.

\section{Individual and Collective Memory}

Theorising about memory occurs at various levels, including at the level of the individual and the level of the group. On an individual level, cognitive psychologists distinghuis between "episodic memory" and "semantic memory" (Tulving 1972). Episodic memories are memories of events one personally experienced. For example, I may episodically remember driving to university this morning, ordering a book on Amazon last week, or attending my $\mathrm{PhD}$ graduation ceremony. When we remember our personal past episodically, we travel back in time, as it were, and visually reexperience the event (Tulving 1985, 2002). These types of memories are accompanied with what cognitive psychologist Endel Tulving refers to as "autonoetic consciousness", which is characterised as follows:

"Autonoetic consciousness (self-knowing) is the name given to the kind of consciousness that mediates an individual's awareness of his or her existence and identity in subjective time extending from the personal past through the present to the personal future. It provides the characteristic phenomenal flavour of the experience of remembering" (Tulving 1985, p. 1).

This type of consciousness can be described as the feeling of travelling back in subjective time as to reexperience an event and is a distinguishing characteristic of episodic memory. Semantic memory - by contrast - is propositional in nature, providing knowledge-that about past events. This includes knowing the meaning of words, language, concepts, and norms, as well as general knowledge domains such as politics, geography, and history. Semantic memory also includes memories about one's own past. For example, I semantically remember that I was born in 1981, graduated high school in 1997, and read Aldus Huxley's Brave New World in high school. However, I am unable to retrieve any visual or experiential information about those events. I know that I experienced those events but cannot remember what it was like to be born, graduate from high school, or read Huxley's Brave New World. Episodic remembering has a distinct phenomenal flavour that is lacking in semantic remembering. This distinction is therefore sometimes cashed out in terms of remembering versus knowing.

Theorists in the situated cognition paradigm argue that individual memory is not merely realised in the biological brain but is often situated and sometimes extended and distributed across the embodied brain and environmental resources (Clark and Chalmers 1998; Clowes 2013, 2017; Michaelian and Sutton 2013; Heersmink 2015). The notes we take during a conference in our notebook or on our laptop, for example, may later help us to remember the argument and content of the talks we attended, extending our semantic memory. The photos we take during our holidays, may later 
help us to remember the experiences we had when on holiday, extending our episodic memory (Sutton 2009; Fawns 2019; Heersmink 2020a). In such cases, the external artifact does not trigger the retrieval of a fully formed biological memory. Rather, information in the embodied brain and in the artifact are integrated into a memory. External artifacts can provide informational properties and functions that complement the memory capacities of the embodied brain (Sutton 2010). And when those complementary properties and functions are appropriately integrated into the memory system of the embodied brain, the artifact and agent can be seen as an extended and distributed memory system (Heersmink 2015). On this view, the content and processes of distributed memories are neither located exclusively in the brain nor exclusively in the artifact, but in the interaction between the two (van Dijck 2007).

On a group level, social scientists distinguish between various sorts of social or collective memory. This type of theorising goes back to the work of French sociologist Maurice Halbwachs (1992/1925) who develops the notion of "collective memory", conceptualising how groups remember their past. In an influential paper and building on the work of Halbwachs, Jan Assmann (1995, 2011) distinguishes between two sorts of collective memory, namely "communicative memory" and "cultural memory". To be as precise as I can, I will quote Assmann's definitions in full.

"Communicative memory is non-institutional; it is not supported by any institutions of learning, transmission and interpretation, it is not cultivated by specialists and is not summoned or celebrated on special occasions; it is not formalized and stabilized by any form of material symbolization but lives in everyday interaction and communication and, for this very reason, has only a limited time depth which normally reaches not farther back than 80 years, the time span of three interacting generations" (Assmann 2011, p. 38).

Simplifying, one can characterise communicative memory as living memory that is communicated during everyday informal social interactions. Cultural memory - by contrast - contains information that goes back deeper into the past and is more formal and institutionalised. Assmann writes:

"This information, however, is not committed to everyday communication but intensely formalized and institutionalized. It exists in forms of narratives, songs, dances, rituals, masks, and symbols, specialists such as narrators, bards, maskcarvers, and others are organized in guilds and have to undergo long periods of initiation, instruction, and examination. Moreover, it requires for its actualization certain occasions when the community comes together for some celebration or other" (Assmann 2011, p. 38).

Again simplifying, one can characterise cultural memory as formalised and institutionalised historical knowledge materialised in artifacts, practices, and memory specialists. So, when you talk to your friend about the global financial crises of 2009, it is an example of communicative memory, but when you participate in a commemorative service to celebrate the end of WW1 or read about it in a history book, it is an example of cultural memory. 
I want to problematise the analytical and empirical value of Assmann's distinction. Whilst these categories may be helpful in identifying clustered characteristics in the overall conceptual landscape of collective memory, there are too many grey areas and there is too much overlap for the categories to be analytically helpful. Roughly, communicative memory is about remembering the recent past through informal conversations, whereas cultural memory is about remembering the deeper past through formalised methods such as rituals, commemorative services, textbooks, documentaries, etc. However, the recent past is also remembered through formal methods such as monuments, textbooks, documentaries, and Wikipedia pages. For example, there are many public spaces, monuments, and commemorative practices to remember the Yugoslav wars in specific ways. The Yugoslav wars happened in the 1990s and so are still in living memory. Conversely, the deeper past is also remembered through informal conversations. We may informally talk about the fall of Rome, the rise of the Han dynasty, or the French revolution over drinks with our friends or colleagues. Admittedly, knowledge about the deeper past is often first obtained through lectures, textbooks, documentaries, newspapers, or other popular media. The main way to learn about these events is through cultural artifacts, as they are no longer in living memory. ${ }^{4}$

I do find the timeframe of living memory versus historical memory helpful. One could (in principle) talk to a person who has lived through WW2 and, in that way, obtain first-personal information about what it was like to live through WW2, but one cannot talk to a person who lived through the American civil war. The distinction between living memory and historical memory is relevant for group identity, because the recent past is often more important than the deeper past for the identity of the group $^{5}$ (Manier and Hirst 2008). For example, the Dutch collectively commemorate the end of WW2 on the 5th of May each year (which is when the Dutch were liberated by the allied forces), but not the end of the Dutch-Portuguese War which ended in 1661. The last 80-100 years are, in most cases, more important in shaping the present identity of a group than what happened in historical memory.

Episodic and semantic memory systems interface with the wider cultural world in various ways. Cognitive psychologists David Manier and William Hirst (2008) develop a taxonomy of collective memories based on the distinction between episodic and semantic memory. They distinguish between "collective episodic memory" and "collective semantic memory". When a family of five goes on holiday to Australia, they all have episodic memories of the same events. So, they share similar episodic memories, which may be talked about during reminiscing, perhaps aided when viewing photos or videos of their holiday. Episodic memories may similarly be shared amongst a group of fans of a sports team, a religious group, members at a political rally, or a group of friends at a music show. Collective semantic memories - by contrast - are not experiential in nature but provide knowledge-that about past events. For example, collective memories about WW2 are important for national identity in many countries, collective memories about the suicide of Kurt Cobain in 1994 are important for the identity of alternative rock fans, and collective memories about the death of George Floyd in 2020

\footnotetext{
${ }^{4}$ Some oral cultures such as those of the Australian Aboriginals do transfer stories across many generations purely through social story telling. I'll get back to this in section 6 .

5 I say "often", as there are also cases in which the opposite happens. A reviewer pointed out that human rights violations in Guantanamo happened a few years ago, but that didn't shape American identity in a strong manner, which is more influenced by older events in this respect.
} 
are important for the identity of civil rights movements. Also, note that not just any collective memory is relevant for group identity. Most British people will remember the global financial crisis of 2009, but it is not essential for being British. However, memories of the terrorist attacks in London in 2005 as a cultural event are much more central to British identity. So, memories must not only be shared amongst group members, but they must also be relevant to the group in some distinct way (Hirst and Manier 2008).

Some collective semantic memories are purely propositional, for example remembering that the Dutch-Portuguese War which ended in 1661. Other collective memories go beyond mere semantic or propositional content. We obtain memories through visual media like the news, photos in newspapers, documentaries, YouTube videos, and so on. These memories are not merely propositional in nature, but do have some sort of experiential component. Memories obtained through external visual media like photos and videos can be seen as a derived form of episodic memory. For example, I did not personally experience the death of George Floyd in 2020 and, in that sense, have no episodic memories of it. I only remember what it looks like in a video of it. My embodied presence is lacking in such experiences and therefore memories of such disembodied, but still visual, experiences can be seen as episodic in a derivative or mediated manner. I will therefore refer to such memories are "mediated episodic memories", as they are memories of events mediated through visual means. Such memories go beyond mere propositional knowledge but are not full-blown episodic either. A further distinction can be made between collective memories of events that happened before and during one's lifetime. WW2 happened before my lifetime, but George Floyd's death happened during my lifetime. I have not lived through events constituting WW2, whereas I have lived through the media attention and controversy of George Floyd's death as well as the civil right protests caused by it.

\section{Small-Scale and Large-Scale Collective Memory}

Theorising on collective memory focusses on small-scale groups and on large-scale groups (Michaelian and Sutton 2017). Small-scale groups include, for example, a couple, a family, or a group of friends or colleagues. Large-scale groups include, for example, a religious group or a nation. Consider first an example of a small-scale group remembering an event relevant for their identity as a group. When trying to remember the name of the show they saw during their honeymoon, a husband and wife could not remember that name individually. But when they give each other cues, the husband and wife integrate information stored in their individual brains to jointly reconstruct the memory (Harris et al. 2014). Note that this is an example of what Manier and Hirst (2008) call collective episodic memory.

Wife: And we went to two shows, can you remember what they were called?

Husband: We did. One was a musical, or were they both? I don't ... no ... one ...

Wife: John Hanson was in it.

Husband: Desert Song. 
Wife: Desert Song, that's it, I couldn't remember what it was called, but yes, I knew John Hanson was in it.

Husband: Yes.

In this example, the processes of remembering as well as the content of the constructed memory are distributed across both the husband and wife. They form an emergent and integrated memory system that knows more than the sum of its parts. Similar sorts of distributed memory systems may exist in families, a group of friends or colleagues, and other small-scale groups that know each other well. Psychologist Daniel Wegner (1986) refers to such integrated cognitive units as transactive memory systems. A conservative reading of small-scale collective memory would merely suggest that remembering is causally influenced by other people. A more radical interpretation, one that I endorse, would suggest that the content and processes of remembering are distributed across members of the group. On this view, memory systems are not realised exclusively in an embodied brain, but are realised by two (or more) people whose memory systems are properly integrated.

Collective memories pertaining to the identity of larger groups can likewise be distributed across two or more members of a group. For example, drawing inspiration from the above example, one may image the following conversation between a husband and wife about why Australia Day is commemorated on January the 26th.

Wife: I know Australia Day is commemorated on the 26th of January.

Husband: Right, it has something to do with when the first British settlers arrived.

Wife: I can't quite remember when that was.

Husband: Wasn't that somewhere in the eighteenth century.

Wife: I think it was in 1788.

Husband: Yes, that's right.

In this case, a collective semantic memory is constructed by integrating information stored in different brains. The take home message here is that we sometimes remember events in the historical narrative of the cultural groups we self-identify with only when interacting with other people in a particular way. It is important to note that distributed and transactive memory systems are limited to a relatively small number of people. In larger groups, such transactive remembering becomes intractable, although perhaps not completely impossible. Collective memory in larger groups thus takes a different form, in that one may merely share similar semantic memories about the past of the group, but these are not distributed.

In a thoughtful review of the collective memory literature, Hirst and Manier (2008) outline a spectrum in which scholars argue that collective memories are located in the individual or in the world. Some sociologists argue that collective memories are located in the world (Irwin-Zarecka 1994; Olick 1999), whereas psychologists tend to argue they are located in the individual. Sociologist Iwona Irwin-Zarecka, for example, argues that "a collective memory - as a set of ideas, images, and feelings about the past - is best located not in the minds of individuals, but in the resources they share" (Irwin-Zarecka 1994, p. 4). Theorists claiming that collective memories are located in the world do not deny that individuals do the remembering. So, when I learn the Dutch- 
Portuguese war ended in 1661 by reading it in a history book, that collective memory is first located in an artifact and then also in my brain. Artifacts obviously do not remember themselves, only humans do. For theorists focusing on collective memories in the world, the salient issues are social processes and mechanisms that govern what and how is remembered at the group level. For those theorists, the relevant questions are: What is included in national archives and history books, and who decides what is included, which monuments and statues are erected and which ones are torn down, which events do journalists and historians write about, how do collective memories spread across a community, etc. Such questions can be political and normative in nature.

Psychologists, on the other hand, often utilise a "methodological individualism", which suggests isolating and demarcating the individual from its environment. On that view, all cognitive and affective states, including collective memories, are located in the individual. Memories, on this view, are never stored or located in the world. Such theorists focus on processes of encoding, storage, and retrieval, as they unfold in the individual's embodied brain. The view I defend is that when collective memories are properly distributed across two or more individuals or across an individual and an artifact, they are located in both. We thus need to enlarge the unit of analysis from an individual to an individual interacting with other individuals or artifacts. Philosopher John Sutton points out that such a view invites use to focus on memory traces as dispositional states in larger distributed systems. He writes:

"Such dispositional states can take the form of information or habits or artifacts, and may be widely distributed across different people and across records or instruments or rituals, with no single individual or archive necessarily holding more than partial or incomplete traces or resources: these are then merged or compiled often on the fly, in the moment, for some particular purpose, and then perhaps recoded or reconsolidated or restored in transformed state" (2008, p. 31).

Merely looking up or asking for information about historical events would not count as a genuine case of extended and distributed memory. For information to be appropriately integrated into the memory systems of its users, it must satisfy a number of conditions (Heersmink 2015). We must reciprocally interact with the information, it must be easily accessible, the relation between the resource and person must be durable, the information must be trustworthy, easy to find, and easy to interpret. Merely looking up information in a history book or Wikipedia does not rank high on some of those key dimensions (Heersmink and Sutton 2020). In particular, looking up information that is created by someone else has a one-way causal information flow structure preventing deep cognitive integration into onboard memory systems, which requires two-way or reciprocal information flow (Clark 1997). In such cases, collective semantic memories are not extended. They are then first located in the world and then also in the individual. Collective memory in this sense is not about groups as cognitive agents that remember in the same way as an individual remembers. Rather, it is about how individual members of a cultural group learn about events related to the group by interacting with artifacts such as history books, webpages, documentaries, etc. Such processes of information flow and the spreading of collective memories across a group are important to better understand and I'll identify some of these processes in the final section. 


\section{Materialised Identities}

Following media theorist Sherry Turkle (2007), Heersmink (2018) has referred to artifacts we use to aid us in remembering our personal past as "evocative objects". Examples of such objects include photos, videos, journal entries, souvenirs, mementos, and other memoryevoking objects. When interacting with evocative objects, we typically integrate information in the embodied brain and in the object to construct a personal memory, thereby allowing us to remember our personal past in a way that is quite different from remembering our past without the aid of such objects (Heersmink 2020a). This is important to better understand in itself, but also because it means that the memories constituting our narrative identity are extended and distributed across embodied agent and evocative objects. And because personal memories are the building blocks of the narrative, our narrative is not realised by the brain alone but is realised by and distributed across embodied agents interacting with evocative objects. Therefore, our narrative identity is a distributed and relational structure (Heersmink 2017). A similar phenomenon occurs with cultural identity. So, if the collective memories constituting one's cultural identity are distributed, then cultural identity is distributed, too.

Evocative objects aid us in remembering our personal past. As we have seen, artifacts also play an essential role in remembering our cultural past. Archives, museums, history books, documentaries, webpages, and other media, aid us in remembering the history of our cultural groups, including those associated with our nationality, regionality, religion, profession, hobbies, sports, music, art, gender, social class, political groups, generation, etc. I shall refer to artifacts that aid us in remembering events constituting the historical narrative of cultural groups as "cultural artifacts". Evocative objects tend to be personal objects such as photos, videos, clothing, jewellery, books, music, art, souvenirs, etc. Whereas cultural artifacts tend to be public objects such as monuments, architecture, webpages, documentaries, history books, and other media. However, public objects can also evoke personal memories (e.g., a monument may evoke a personal memory of the previous time you visited it), and personal objects can evoke collective memories (e.g., a history book you own may evoke a collective memory of WW2). So, these categories of memory-evoking objects overlap.

Let me end this section by giving one specific example of how family narratives are materialised in artifacts. Anthropologist Kate Pahl (2004) performed a two-year ethnographic study of narrative practices in family homes. During her observations and interviews, she finds that "artifacts acted as conduits for narratives" (2004, p. 343). For example, in one family, the grandfather had worked in India building railway tracks and used to make train models. Pahl writes: "The trains were displayed in a glass cabinet in the front room. The original train, made by Mary's grandfather, operates as a memento of the family history of building the railways in India (...) and was used by family participants to evoke emotional links to the past" (p. 347-350). The train was first given to Mary by her grandfather and then later given to her son Edward, who now collects trains, including those made by his great-grandfather. Mary's grandfather moved from Ireland to India to work on Indian railways. Mary grew up in India but later moved back to England. For Mary and Edward, the train symbolises and reminds them of their complex family history of migration. So, the cultural identity of the family is materialised in artifacts. Cultural identity is thus not an intrinsic property of embodied brains, but a relational and distributed structure. 


\section{Constructing Cultural Identities}

Up to now, I presented (the relation between) cultural and narrative identity, and argued how different forms of distributed memory are essential in the constitution of these identities. In this section, I draw on the conceptual resources of niche construction theory to better understand how we construct our cultural identities.

Niche construction theory is a relatively recent approach in evolutionary biology, arguing that some organisms actively construct their niche, which has developmental and evolutionary advantages (Odling-Smee et al. 2003). The niche of an organism can be characterised as all the ecological dimensions that have an impact on, or relation to, its survival and reproduction. Such dimensions may include, for example, food availability, mate availability, resource availability, temperature, the presence of predators, parasites, and chemicals, etc. "Niche construction refers to the activities, choices, and metabolic processes of organisms, through which they define, choose, modify, and partly create their own niches" (Laland et al. 2000, p. 132-133). Termites, for example, build mounds, providing colonies with a safe, regulated environment to reproduce and raise their offspring. Doing so, changes the selection pressures to which termites are exposed. Animal niche construction is primarily practical in nature, focussing on their biological needs, meaning that it has to do with foraging, shelter, reproduction, and survival. Human niche construction is different because it goes beyond mere practical, biological purposes.

Human niche construction is threefold:

- Practical: niche construction processes relating to our biological needs (e.g., constructing houses, infrastructure, agriculture).

- Cognitive: niche construction processes relating to our cognitive capacities (e.g., constructing the printing press, books, maps, writing, computer systems).

- Cultural: niche construction processes relating to our cultural identities (e.g., constructing monuments, museums, art, churches, institutions).

These sorts of niche construction processes can overlap. Building houses, for example, is a practical type of niche construction but also has cultural components, in that houses are often not merely for shelter but also express, affirm, and remind one of one's cultural identity. Cognitive niche construction is the process of modifying and utilising parts of the environment as to aid us in completing our cognitive tasks. Humans are quite good at this and have developed many ways to store and use information in the environment. We have developed numeral systems, cartographic systems, diagrams, symbols, alphabets, and languages as well as artifacts to store that information such as clay tablets, papyrus scrolls, books, newspapers, abacuses, computers, and the internet. Most theorising in cognitive niche construction focusses on how we use informational artifacts to complete problem-solving tasks such as navigating, calculating, and remembering facts (Clark 2006; Sterelny 2010; Kendall 2011; Sinha 2015; but compare Fabry 2018). As far as I am aware, it has not been used to theorise about our cultural identities. ${ }^{6}$ In a sense, all human niche construction is cultural in nature, in that

\footnotetext{
${ }^{6}$ Richard Menary (2014) helpfully argues that there is an aesthetic niche going beyond cognitive niche construction but does not theorise about its relation to cultural identity.
} 
constructing artifacts and institutions is an essentially cultural activity. Artifacts are therefore often referred to as material culture. However, in this essay, the phrase "cultural niche construction" refers to niche construction processes relating to our cultural identities.

I identify three broad classes of cultural niche construction processes:

- Building of cultural artifacts and institutions which function as to store collective memories (e.g., building a monument, archive, writing a history book, webpage, newspaper article).

- Transferring of collective memories through institutions, social practices, and artifacts, either within a generation or across generations.

- Using of cultural artifacts which may be done on an individual level (e.g., looking up some historical description of an event in a textbook or webpage) or a collective level (e.g., a commemorative service at a monument).

The building of cultural artifacts and institutions, which are later used to help us remember events in the historical narrative of cultural groups, is a ubiquitous process. ${ }^{7}$ Monuments, statues, plaques, and public spaces are built by governments to commemorate important events in national and regional history. Journalists write newspaper articles and documentary-makers make documentaries about important cultural events. Organisations create archives, libraries, and museums, biographers write books about important historical figures, and historians write books on the history of cultural groups having to do with nationality, regionality, religion, profession, hobbies, sports, music, art, gender, social class, political groups, generation, and families. So, there is a wealth of cultural information materialised in artifacts and institutions that contain collective semantic memories.

Once these artifacts and institutions are built, they are used by people within that generation. Information is then transferred horizontally. Cultural artifacts and institutions are also often passed on to the next generation. Information is then transferred and passed on vertically. To better understand the vertical transfer of collective memories through institutions, social practices, and artifacts, I will draw on a concept from cognitive niche construction, namely what philosopher of biology Kim Sterelny (2003) refers to as "downstream epistemic engineering". He argues that we do not just engineer our current cognitive niche through creating books, maps, and computer systems, but by doing so, we also engineer the cognitive niche of the next generation. We are born in the informational environment that our parent generation has created, our parent generation was born in the informational environment their parent generation has created, and so on. This provides us with enormous cognitive benefits as we do not have to invent, discover, or develop the same information twice. Once information (e.g., a map) is created, it can be passed on to the next generation who often improve that information. Evolutionary biologists Eva Jablonka and Marion Lamb (2005) refer to the transfer of symbolic information such as language, numbers, and maps from one generation to the next as a "symbolic inheritance system". So, we do not just inherit genes from our parents but also an informational niche, resulting in dual inheritance channels, one genetic the other cultural-informational.

\footnotetext{
${ }^{7}$ Building sometimes involves reproducing an artifact, for example when a book or photo is reproduced.
} 
Downstream epistemic engineering and symbolic inheritance are the core mechanism of many collective memory systems, particularly of collective semantic memory. Information about the historical narrative of cultural groups is passed on from one generation to the next. In some cases, the cultural lineage of specific artifacts can date back thousands of years. For example, due to the writings of Greek historian Herodotus, we now know a good deal about ancient Greek culture. His book The Histories, which was published sometime between 426 and $415 \mathrm{BCE}$ and written on papyrus, is generally considered the first historiography written in a narrative form. It tells about ancient traditions, politics, geography, and wars between various cultures that were known in Greece, Western Asia, and Northern Africa at that time. The Histories has been translated in many languages and is still used across the world to better understand ancient Greek culture. It is almost 2500 years old and so has a linage spanning approximately 125 generations. The Histories is perhaps an unusual example but there are many cultural artifacts containing information about past events of specific cultural groups. Trajan's Column in Rome, completed in 113 AD, commemorates Roman emperor Trajan's victory in the Dacian Wars. It contains an elaborate spiral bas relief representing the wars between the Romans and Dacians. Herodotus' The Histories has many copies in different languages and so its lineage has a branching structure, whereas there is only one Trajan's Column and so its lineage is linear. ${ }^{8}$ There are, likewise, many bas reliefs in publicly accessible places in both Western and non-Western cultures, depicting important historical events.

Significantly, stories about the cultural past are also passed on verbally. One of the most impressive examples comes perhaps from Australian Aboriginal cultures. These lack a systematic written language and so their main method for transmitting information about their cultural past is through story telling. Geographer Patrick Nunn (2018) writes that various Aboriginal stories claim Fitzroy Island on the Great Barrier Reef was connected to the mainland. This information is important for Australian Aboriginals because they have a deep spiritual connection to their land. Data from geology confirms this was the case at least 10,000 years ago. If true, it seems as though stories can convey accurate information about events going back 500 generations. Interestingly, it shows that oral histories can contain information about events deeper into our past than information contained in artifacts (e.g., books or bas reliefs). ${ }^{9}$

More contemporary forms of downstream epistemic engineering and symbolic inheritance include webpages, YouTube videos, documentaries, news media, and popular science magazines. For example, the history of the Netherlands has an elaborate Wikipedia page, hundreds of YouTube videos (of varying levels of detail and quality), hundreds of documentaries, many items in both scientific and popular history magazines, and various discussions on internet fora. Smaller-scale cultural groups such as fans of alternative rock, sports teams, or political groups have, likewise - albeit on a much smaller scale - webpages, YouTube videos, items in news media, and in

\footnotetext{
${ }^{8}$ But since the invention of photography, there are now also many photographs of the bas reliefs and so its lineage is now also branching.

${ }^{9}$ This, of course, has to do with written language being invented approximately between 3400 and 3100 BCE in Mesopotamia. Bas reliefs date back much deeper into the past. The oldest petroglyphs (images pecked into the walls of caves or other rock surfaces) date back to approximately 30,000 years ago. Petroglyphs are much older than written language but are (for contemporary scholars) often difficult to interpret. So, they no longer support collective memories of cultural events.
} 
scientific and popular science magazines, depicting their history. Not all members of cultural groups engage with these cultural artifacts in the same degree. But the collective memories are there to tap into for those who are interested.

The use of cultural artifacts as to remember events in the historical narrative of cultural groups is done on both an individual and collective level. Individuals may visit a monument, statue, public space, archive, library, or museum, watch a documentary, read a history book or newspaper article, and by doing so, be reminded or learn about important events in the history of cultural groups. Sometimes, with particularly important events, we collectively participate in a commemorative service. For example, in Australia and New Zealand, people collectively partake in a commemorative service on Anzac Day, a national day of remembrance, during which all Australians and New Zealanders who served and died in all wars, conflicts, and peacekeeping operations are commemorated. These include WW1, WW2, the Vietnam War, the Gulf War, and other armed conflicts. During such services, often held at war memorials around the country, there are commemorative addresses, wreath laying, hymns, the sounding of the Last Post, observance of one minute's silence, and the national anthems are played. These services are broadcasted live on TV and play an important role in Australian national identity (Donoghue and Tranter 2013). Such artifact-scaffolded practices embedded in cultural institutions remind us of events constituting these narratives in a way that is not possible without external aid.

Finally, during such services, collective memories about wars are retrieved from memory, often supplemented with information from other people's memories of war (e.g., from the speeches given by veterans and other people). Such services have a strong affective significance for most participants, particularly for those who participated in the wars or have lost people in the wars. Some affective states, or the specific form they take, are only manifested during such services (Wilson 2001). Such affective states are (to varying degrees) shared across the group, in that most participants will feel similar (Huebner 2011; Von Scheve and Ismer 2013). The sharing of emotions (e.g., grief, sadness, sense of unity) is important for one's sense of cultural identity, creating a sense of belonging.

\section{Conclusion}

This essay has conceptualised one way to look at the relation between cultural identity, collective memory, and artifacts. Social interactions with other people as well as artifact-scaffolded practices embedded in institutions help us to remember past events in the historical narrative that characterises our cultural identity. I argued that cultural identity is materialised when we retrieve and construct collective memories by integrating information from our biological memory with information in artifacts and other people's brains. To better understand how our cultural identities are materialised, I drew on niche construction theory from evolutionary biology and identified three types of cultural niche construction processes, namely the building, transferring, and using of cultural artifacts. 


\section{References}

Assmann, J. 1995. Collective memory and cultural identity. New German Critique 65: 125-133.

Assmann, J. 2011. Communicative and cultural memory. In Cultural memories, ed. P. Meusburger, M. Heffernan, and E. Wunder, 15-27. Dordrecht: Springer.

Clark, A. 1997. Being there: Putting brain, body, and world together again. Cambridge: MIT Press.

Clark, A. 2006. Language, embodiment, and the cognitive niche. Trends in Cognitive Science 10 (8): 370374.

Clark, A., and D. Chalmers. 1998. The extended mind. Analysis 58 (1): 10-23.

Clowes, R. 2013. The cognitive integration of e-memory. Review of Philosophy \& Psychology 4 (1): 107-133.

Clowes, R. 2017. Extended memory. In Routledge handbook of the philosophy of memory, ed. S. Bernecker and K. Michaelian, 243-255. London: Routledge.

Donoghue, J., and B. Tranter. 2013. The Anzacs: Military influences on Australian identity. Journal of Sociology 51 (3): 449-463.

Ellemers, N., R. Spears, and B. Doosje. 2002. Self and social identity. Annual Review of Psychology 53: 161186.

Fabry, R. 2018. Spontaneous cognition and epistemic agency in the cognitive niche. Frontiers in Psychology 9 (931). https://doi.org/10.3389/fpsyg.2018.00931.

Fawns, T. 2019. Blended memory: A framework for understanding distributed autobiographical remembering with photography. Memory Studies. 13: 901-916. https://doi.org/10.1177/1750698019829891.

Gallagher, S. 2000. Philosophical conceptions of the self: Implications for cognitive science. Trends in Cognitive Science 4 (1): 14-21.

Halbwachs, M. 1992/1925. On collective memory. Translated by L. Coser. Chicago: University of Chicago Press.

Harris, C., A. Barnier, J. Sutton, and P. Keil. 2014. Couples as socially distributed cognitive systems: Remembering in everyday social and material contexts. Memory Studies 7 (3): 285-297.

Heersmink, R. 2015. Dimensions of integration in embedded and extended cognitive systems. Phenomenology and the Cognitive Sciences 14 (3): 577-598.

Heersmink, R. 2017. Distributed selves: Personal identity and extended memory systems. Synthese 194 (8): 3135-3151.

Heersmink, R. 2018. The narrative self, distributed memory, and evocative objects. Philosophical Studies 175 (8): 1829-1849.

Heersmink, R. 2020a. Extended mind and artifactual autobiographical memory. Mind \& Language. https:// doi.org/10.1111/mila.12353.

Heersmink, R. 2020b. Narrative niche construction: Memory ecologies and distributed narrative identities. Biology and Philosophy 35 (5): 1-23.

Heersmink, R., and J. Sutton. 2020. Cognition and the web: Extended, transactive, or scaffolded? Erkenntnis 85 (1): 139-164.

Hirst, W., and D. Manier. 2008. Towards a psychology of collective memory. Memory 16 (3): 183-200.

Huebner, B. 2011. Genuinely collective emotions. European Journal for Philosophy of Science 1: 89-118.

Irwin-Zarecka, I. 1994. Frames of remembrance: The dynamics of collective memory. New Brunswick: Transaction.

Jablonka, E., and M. Lamb. 2005. Evolution in four dimensions: Genetic, epigenetic, behavioral and symbolic variation in the history of life. Cambridge: MIT Press.

Jenkins, R. 2014. Social identity. London: Routledge.

Kendall, J. 2011. Cultural niche construction and human learning environments: Investigating sociocultural perspectives. Biological Theory 6 (3): 241-250.

Laland, K., J. Odling-Smee, and M. Feldman. 2000. Niche construction, biological evolution, and cultural change. Behavioral and Brain Sciences 23: 131-175.

László, J. 2007. The science of stories: An introduction to narrative psychology. London: Routledge.

Liu, J., and J. László. 2007. A narrative theory of history and identity. In Social representations and identity: Content, process, and power, ed. G. Moloney and I. Walker, 85-107. New York: Palgrave Macmillan.

Manier, D., and W. Hirst. 2008. A cognitive taxonomy of collective memories. In Cultural memory studies: An international and interdisciplinary handbook, ed. A. Nunning and A. Eril, 253-262. Berlin: de Gruyter.

Menary, R. 2014. The aesthetic niche. British Journal of Aesthetics 54 (4): 471-475.

Michaelian, K., and J. Sutton. 2013. Distributed cognition and memory research: History and current directions. Review of Philosophy and Psychology 4 (1): 1-24. 
Michaelian, K., \& Sutton, J. 2017. Memory. In Stanford encyclopedia of philosophy, ed. N. Zalta. URL: https://plato.stanford.edu/entries/memory/

Nunn, P. 2018. The edge of memory: Ancient stories, oral tradition, and the post-glacial world. London: Bloomsbury Publishing.

Odling-Smee, J., K. Laland, and M. Feldman. 2003. Niche construction: The neglected process in evolution. Princeton: Princeton University Press.

Olick, J. 1999. Collective memory: The two cultures. Sociological Theory 7: 333-348.

Pahl, K. 2004. Narratives, artifacts and cultural identities: An ethnographic study of communicative practices in homes. Linguistics and Education 15 (4): 339-358.

Ricoeur, P. 1984. Time and narrative, volume 1. Translated by K. Blamey \& D. Pellauer. Chicago: University of Chicago Press.

Schatz, R., and H. Lavine. 2007. Waving the flag: National symbolism, social identity, and political engagement. Political Psychology 28 (3): 329-355.

Schechtman, M. 1996. The constitution of selves. Ithaca: Cornell University Press.

Schechtman, M. 2011. The narrative self. In The Oxford handbook of the self, ed. S. Gallagher, 394-416. Oxford: Oxford University Press.

Schlicht, T. 2018. Experiencing organisms: From mineness to subject of experience. Philosophical Studies 175: 2447-2474.

Sinha, C. 2015. Language and other artifacts: Socio-cultural dynamics of niche construction. Frontiers in Psychology 6 (1601). https://doi.org/10.3389/fpsyg.2015.01601.

Sterelny, K. 2003. Thought in a hostile world: The evolution of human cognition. Oxford: Blackwell.

Sterelny, K. 2010. Minds: Extended or scaffolded? Phenomenology and the Cognitive Sciences 9 (4): $465-$ 481.

Sutton, J. 2008. Between individual and collective memory: Coordination, interaction, distribution. Social Research 75 (1): 23-48.

Sutton, J. 2009. Remembering. In The Cambridge handbook of situated cognition, ed. P. Robbins and M. Aydede, 217-235. Cambridge: Cambridge University Press.

Sutton, J. 2010. Exograms and interdisciplinarity: History, the extended mind, and the civilizing process. In The extended mind, ed. R. Menary, 189-225. Cambridge: MIT Press.

Tajfel, H. 1972. Social categorization. English manuscript of 'La catégorisation sociale'. In Introduction à la psychologie sociale, ed. S. Moscovici, 272-302. Paris: Larousse.

Tulving, E. 1972. Episodic and semantic memory. In Organization of memory, ed. E. Tulving and W. Donaldson, 382-404. New York: Academic Press.

Tulving, E. 1985. Memory and consciousness. Canadian Psychology/Psychologie Canadienne 26 (1): 1-12.

Tulving, E. 2002. Episodic memory: From mind to brain. Annual Review of Psychology 53 (1): 1-25.

Turkle, S., ed. 2007. Evocative objects: Things we think with. Cambridge: MIT Press.

Van Dijck, J. 2007. Mediated memories in the digital age. Stanford: Stanford University Press.

Von Scheve, C., and S. Ismer. 2013. Towards a theory of collective emotions. Emotion Review 5 (4): 406413.

Wang, Q. 2008. On the cultural constitution of collective memory. Memory 16 (3): 305-317.

Wegner, D.M. 1986. Transactive memory: A contemporary analysis of the group mind. In Theories of group behaviour, ed. B. Mullen and G.R. Goethals, 185-208. New York: Springer-Verlag.

Wilson, R. 2001. Group-level cognition. Philosophy of Science 68: 262-273.

Wilson, R. 2005. Collective memory, group minds, and the extended mind. Cognitive Processing 6: 227-236.

Publisher's Note Springer Nature remains neutral with regard to jurisdictional claims in published maps and institutional affiliations. 